\title{
Treatment with a GPIlb/ Illa Antagonist Inhibits Thrombin Generation in Platelet Rich Plasma from Patients
}

\author{
I. M. L. W. Keularts, S. Béguin, C. de Zwaan, H. C. Hemker \\ From the Department of Bioc hemistry, Ca rdiova sc ular Resea rch Institute Maa stric ht, University Ma astric ht, \\ and the ${ }^{1}$ Department of Cardiology, Academic Hospital, Ma astric ht, Maastric ht, The Netherlands
}

\section{Summary}

Infusion of the GPIIb/IIIa-inhibitor MK383 inhibits thrombin generation in platelet rich plasma by interfering with the production of platelet procoagulant phospholipid exposure. The effect is similar to that of $0.2 \mathrm{U} / \mathrm{ml}$ of heparin. Heparin infusion, well known to inhibit thrombin generation by fostering antithrombin activity, inhibits the formation of platelet-derived procoagulant microparticles, probably by decreasing the formation of free thrombin, which, under our circumstances, is the main platelet activator.

\section{Introduction}

It is still generally accepted that anti-platelet and anti-coagulant action are entirely different modes of action of antithrombotic drugs. On the basis of the observation that in vitro an antibody that blocks GPIIb:IIIa receptor of platelets also inhibits thrombin generation in platelet rich plasma (PRP), it has been surmised, however, that interfering with this platelet function may owe its effect not only to inhibition of platelet aggregation but also to dampening of thrombin generation through inhibition of the exposure of procoagulant phospholipids by the platelets (1-3). To test this hypothesis in a clinical situation, we measured thrombin generation in PRP from patients receiving MK-383, a non-peptide antagonist of GPIIb:IIIa that mimics the RGD sequence in fibrinogen, that is highly selective for the GPIIb:IIIa receptor and that is active in the $\mathrm{nM}$ range (5).

In the course of a clinical trial, approved by the ethics commission of our hospital, in which patients, upon informed consent, received at random either heparin (a $5000 \mathrm{IU}$ i.v. bolus followed by infusion of $1000 \mathrm{IU}$ per h for $48 \mathrm{~h}$ ) or MK-383 (a loading dose of $0.6 \mu \mathrm{g} / \mathrm{kg} / \mathrm{min}$ over $30 \mathrm{~min}$ and $0.15 \mu \mathrm{g} / \mathrm{kg} / \mathrm{min}$ over the next $47.5 \mathrm{~h}$ ), we had the opportunity to study eight patients with unstable angina or non-Q-wave myocardial infarction, receiving one or the other drug.

\section{Materials and Methods}

The first blood sample was drawn not earlier than $3 \mathrm{~h}$ after the start of the infusion. More than 18 h, i.e. over 6 times the half-life of the drugs (5), after the infusion had stopped, a control sample was drawn.

Platelet rich plasma (PRP) was obtained by centrifugation of freshly drawn citrate blood (1 volume trisodium citrate $0.129 \mathrm{M}$ to 9 volumes of blood) at $265 \times \mathrm{g}, 10 \mathrm{~min}$ at $15^{\circ} \mathrm{C}$. Platelet poor plasma (PPP) was made by double centrifugation at $2900 \times \mathrm{g}, 10 \mathrm{~min}$ at $15^{\circ} \mathrm{C}$. Platelets were counted with a Coulter Counter MD18 and PRP was adjusted to 300 platelets/nl with autologous PPP.

Correspondence to: Dr. H. C. Hemker, Dept. of Biochemistry, Maastricht University, PO Box 616, 6200MD Maastricht, The Netherlands - Tel.: +31 43 388 16 75; FAX Number: +31 433670988
Thrombin generation curves in PRP were obtained by subsampling from recalcified PRP into a chromogenic substrate of thrombin (S2238) as described in detail earlier $(6,7)$. The endogenous thrombin potential (ETP) i.e. the area under the curve, was assessed from these experiments. After thrombin generation was over ( $\mathrm{t}>20 \mathrm{~min}$ ), sera were collected on ice, centrifuged for $1 \mathrm{~min}$ at $10,000 \times \mathrm{g}$ and frozen for later analyses of platelet membrane-derived procoagulant activity (PMPA) and residual prothrombin. For the PMPA determination, $7.5 \mu \mathrm{l}$ of serum was added to $142.5 \mu \mathrm{l}$ Hepes buffer A, $\mathrm{pH} 7.35$ containing $8 \mathrm{mM} \mathrm{CaCl}_{2}, 7 \mathrm{nM}$ bovine $\mathrm{F} \mathrm{Va}, 0.3 \mathrm{nM} \mathrm{F} \mathrm{X}$ and $2 \mu \mathrm{M}$ bovine prothrombin. After 2 and 4 min incubation at $37^{\circ} \mathrm{C}, 10 \mu \mathrm{l}$ of the reaction mixture was tested for thrombin activity in $4 \mathrm{mM} \mathrm{S} 2238$ in the same buffer (8).

For the residual prothrombin determination, the increase in thrombin-like amidolytic activity caused by the addition of $1 \mu \mathrm{M}$ staphylocoagulase to serum or 1:40 diluted PPP (in Hepes buffer) was determined. The residual prothrombin in serum is expressed as $\%$ of that of the original plasma.

\section{Results and Disc ussion}

MK-383 significantly inhibits thrombin generation in PRP but not in PPP (Table 1, Fig 1). This shows that the action of the drug is due to a reduction of platelet derived procoagulant activity and not to an influence on the coagulation system. This is corroborated by the observation that ionomycin, a drug that induces platelet procoagulant activity, bypassing the physiological mechanisms (9), relieves the inhibition obtained by blocking GPIIb/IIIa (results not shown). The inhibition observed was reflected in prothrombin consumption and formation of microparticles in serum (Table 1).

Table 1 Effect of administration of MK-383 or heparin on the coagulation system in PPP and PRP.

\begin{tabular}{lcccc}
\hline & ETP - PRP & PMPA & $\begin{array}{c}\text { Residual } \\
\text { Prothrombin } \\
\text { (nMmin) }\end{array}$ & ETP - PPP \\
& (arb. units) & (\% plasma) & (nM.min) \\
\hline MK-383 & $\mathbf{3 2 7} \pm \mathbf{3 6}$ & $\mathbf{8 8} \pm \mathbf{2 1}$ & $\mathbf{1 1} \pm \mathbf{3}$ & $\mathbf{4 0 7} \pm 33$ \\
During treatment & $429 \pm 27$ & $149 \pm 23$ & $5 \pm 1$ & $411 \pm 31$ \\
After treatment & 76.2 & 59.1 & & 98.8 \\
\% of initial & & & & \\
& & & & \\
Heparin & $\mathbf{3 8} \pm \mathbf{2 2}$ & $\mathbf{4 9} \pm \mathbf{4 5}$ & $\mathbf{6 8} \pm \mathbf{1 6}$ & $\mathbf{7 1} \pm \mathbf{2 7}$ \\
During treatment & $421 \pm 9$ & $162 \pm 34$ & $8.6 \pm 3$ & $450 \pm 22$ \\
After treatment & 8.9 & $\mathbf{3 0 . 2}$ & & $\mathbf{1 5 . 7}$ \\
\% of initial & & &
\end{tabular}

Figures indicate mean $\pm S D, n=8$. Significant differences during the treatment, as determined by the Wilcoxon signed rank test for paired data, are in bold type. 


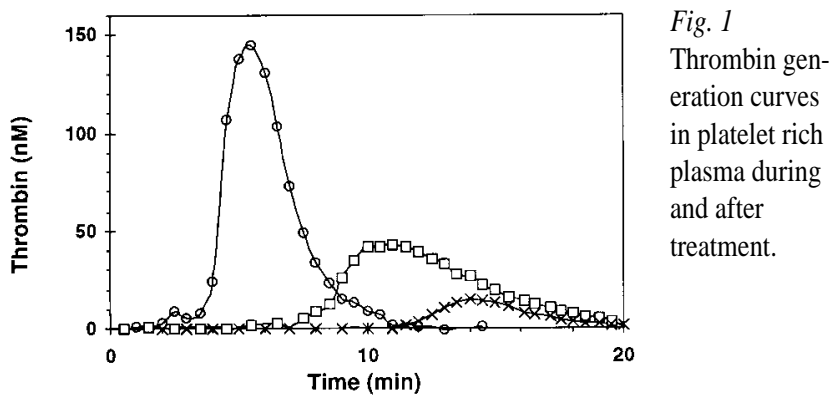

Control: MK-383 infused patient $24 \mathrm{~h}$ after the end of drug infusion (the control curve of the heparin treated patient was not significantly different)

P Patient during infusion of MK 383

$\times$ Patient during infusion of heparin

In heparin treatment, the reduction of thrombin generation is due to the increase of antithrombin activity and thus observed in PPP. Interestingly, the formation of procoagulant microparticles is also significantly reduced by heparin treatment (Table 1). We think that this is secondary to the strong inhibition of the main platelet activator i.e. thrombin. This observation shows that a GPIIb:IIIa antagonist acts as an anticoagulant in PRP, and therefore probably also in vivo. Its effect is approximately equal to that obtained with $0.2 \mathrm{U} / \mathrm{ml}$ unfractionated heparin added to normal PRP (7). On the other hand, the anticoagulant action of heparin interferes with the procoagulant function of platelets.

Our results stress the importance of the interaction between platelets and the coagulation system. Further support for this view can be obtained from the observation that aspirin reduces thrombin generation in blood (10). Also the fact that both oral anticoagulation (11) and heparin treatment (12), two essentially different modes of anticoagulation, reduce coronary reinfarction, is suggestive of a narrow link between thrombin generation and, largely platelet-mediated, arterial thrombosis.

The large majority of studies on the coagulation system are carried out in PPP; platelet adhesion and aggregation on the other hand are most often studied in anticoagulated blood. Our results show that the traditional distinction between anti-platelet and anti-coagulant therapy fades as soon as the integrated system of platelets and coagulation factors is studied. This may be a helpful insight for the development of new antithrombotics.

\section{Acknowledgement}

This study was supported by Program Grant 900-526-192 from the Dutch Organisation for Scientific Research (N.W.O.).

\section{References}

1. Reverter JC, Béguin S, Kessels H, Kumar R, Hemker HC, Coller BS. Inhibition of platelet mediated tissue induced thrombin generation by mouse/human chimeric 7E3 antibody: Potential implications for the effect of c7E3 Fab treatment on acute thrombosis and "Clinical Restenosis". J Clin Invest 1996; 98: 863-74.

2. Pedicord DL, Mousa SA, Dicker IB. Platelet GPIIb/IIIa antagonists inhibit platelet procoagulant activity. Thromb Haemost, Supplement 1997, p. 660, Abstract PS-2693.

3. Herault JP, Peyrou V, Savi P, Bernat A, Herbert JM. Effect of SR121566A, a potent GPIIb/IIIa antagonist on platelet-mediated thrombin generation in vitro and in vivo. Thromb Haemost 1998; 79: 383-8.

4. Gould RJ, Chang CTC, Lynch RJ, et al. MK-0383 is a potent non-peptide mimic of RGD that inhibits glycoprotein IIb/IIIa. Thromb Haemost 1993: 69: 976.

5. Barrett JS, Murphy G, Peerlinck K, De Lepeleire I, Gould RJ, Panebianco D, Hand E, Deckmyn H, Vermylen J, Arnout J. Pharmacokinetics and pharmacodynamics of MK-383, a selective non-peptide platelet glycoproteinIIb/IIIa receptor antagonist, in healthy men. Clin Pharmacol \& Ther 1994; 56: $377-88$

6. Hemker HC, Willems GM, Béguin S. A computer assisted method to obtain the prothrombin activation velocity in whole plasma independent of thrombin decay processes. Thromb Haemost 1986; 56: 9-17.

7. Béguin S, Lindhout T, Hemker HC. The effect of trace amounts of tissue factor on thrombin generation in PRP, its inhibition by heparin. Thromb Haemost 1989; 61: 25-9.

8. Wagenvoord RJ, Hendrix HH, Hu Kai, Hemker HC. A chromogenic test to determine the procoagulant phospholipids in platelet rich plasma and whole blood. Thromb Haemost 1994; 72: 582-7.

9. Bevers EM, Comfurius P, van Rijn JLML, Hemker HC, Zwaal RFA. Generation of prothrombin converting activity and the exposure of phosphatidylserine at the outer surface of platelets. Eur J Biochem 1982; 122: 429-36.

10. Kessels H, Béguin S, Andree H, Hemker HC. Measurement of thrombin generation whole blood - The effect of heparin and aspirin. Thromb Haemost 1994; 72: 78-83.

11. Sixty-Plus Reinfarction Study Research Group. A double blind trial to assess long-term oral anticoagulant therapy in elderly patients after myocardial infarction. Lancet 1980; 2: 989-94.

12. Neri-Serneri GG, Rovelli F, Gensine GF, Pirelli S, Carnovali M, Fortini A. Effectiveness of low-dose heparin in prevention of myocardial reinfarction. Lancet 1987; 25: 937-42.

Received March 17, 1998 Accepted after revision May 12, 1998 